\title{
Metadata Kavramı
}

\section{The Concept of Metadata}

\section{Mehmet Emin Küçük* ve Umut $\mathrm{Al}^{\star \star}$}

\begin{abstract}
$\ddot{O} z$
internet. kullanicilarına iletişinde hiz ve kolaylıklar sunmakla birlikte. bilgi erişim açısından bir dizi sorunu da beraberinde getirmiştir. Bu sorunlan çevrim içi ortamda yer alan belgelerin tamamının kapsanması, dizinlenmesi. seçimi. erişimi ve bu karmaşık çevrim içi ortamda farkedilebilmek olarak özetlemek olanaklıdır. Çahı̧mamizda. internet bilgi kaynaklarının düzenlenmesi ve erişim sorunlarına çözüm olarak ortaya çıkan metadata kavramı açıklanarak, metadata oluşturma araçları ve metadata standartlarından bazıları tanıtılmıştır.
\end{abstract}

Anahtar sözcükler: Internet, Metadata. Metadata standartları. Elektronik kaynaklar-kataloglama, Metadata araçları.

\begin{abstract}
The internet provides fast and effective communication. However, it has also introduced several problems which can be categorised as coverage. indexing. selection and retrieval of documents. In this descriptive study. the concept of metadata, which emerged as a solution for the problems of organising and retrieving internet resources, and some of the metadata creation tools and the standards are described.
\end{abstract}

Keywords: Internet, Metadata. Metadata standards, Electronic resources-cataloging, Metadata tools.

\section{Giriş: Internet ve Erişim Sorunları}

Son yıllarda hepimizin gözlediği gibi İnternet büyük bir hızla büyümekte, uzun yıllardır literatürde "bilgi patlaması" adı verilen olguya bu ortamda daha yakından tanık olmaktayız. Internet'in büyüklüğü bir bașka deyişle içerdiği kaynak sayısını ifade etmek amacıyla bir dizi kestirimde bulunulmuş olmakla bir-

\footnotetext{
- Yrc. Doç. Dr.: Hacettepe Ünversitesi Bilgi ve Belge Vönetim Bölümü (mkucuk@haceitepeedu.lr).

* Airs. Gïr.: Hacettope Universitesi Biig!ve Eelge Yönetmi Bciümü rumutal@nacetteoe.equ.tr:.
} 
likte kesin bir rakam verebilmek olanaksızdır. Gray (1996) tarafından Web sitesi sayılarına ilişkin yapılan çalışmada şu veriler elde edilmiştir:

\begin{tabular}{rc}
\hline Ay/Yıl & Web sitesi sayısı \\
\hline $6 / 93$ & 130 \\
$12 / 93$ & 623 \\
$6 / 94$ & 2738 \\
$12 / 94$ & 10022 \\
$6 / 95$ & 23500 \\
$1 / 96$ & 100000 \\
\hline
\end{tabular}

Diğer bir kestirimde ise, 1997 başında 100 milyon, 1999 yıl'। ortasında ise 800 milyon Web sayfası tespit edilmiştir (Lowe, 2000). Netcraft (url $\left.{ }^{1}\right)^{*}$ tarafından yapılan çalışmada da Kasım 2001 tarihinde sunucu adına sahip 36.458.394 sitenin varl/ğı belirlenmiştir (Netcraft, 2001). Bu sitelerde yer alan dizinlenebilir belge sayısı ise bir varsayım olmaktan öteye geçemeyecektir. Arama motorlarınca belirtilen, dizinlenen Web saytalarının karşılaştırmalı tablosu aşağıda verilmiştir. Tablo incelendiğinde bir milyarın üzerinde Web belgesinin Google (url ${ }^{2}$ ) tarafından dizinlendiği görülmektedir.

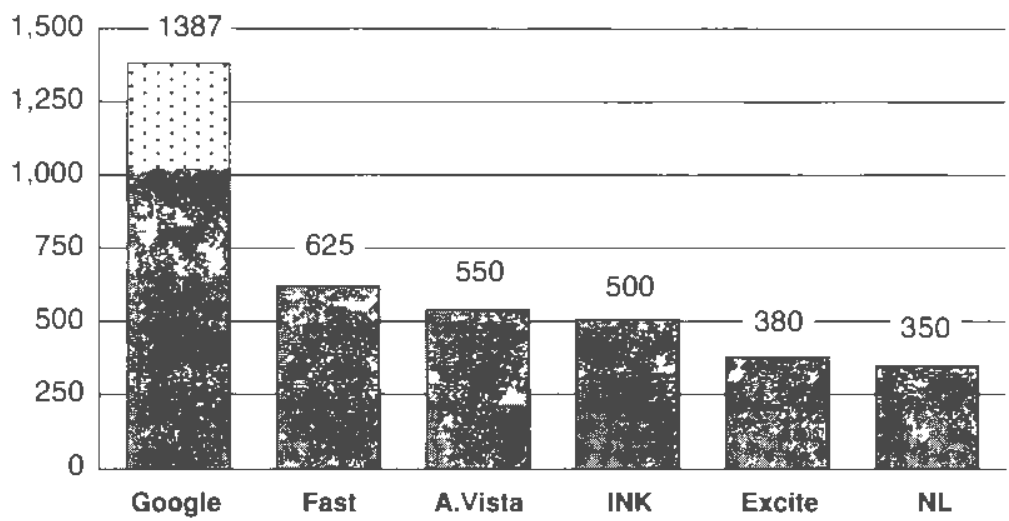

Kaynak: Sullivan, 2001 The Search Engine Report."

* Okumay kolaylaştrmak için Web adresteri numaralandirlarak kaynakçadan sonra URL Listesi altinda verilmişstir.

"* Grafikteki rakamiar milyonia çarpumalthdr. 
Web belgelerinin artışının yanı sıra İnternet kullanıcılarının sayısının da hızlı bir şekilde artığı gözlemlenmektedir. Nua (url $\left.{ }^{3}\right)$ (2001) tarafından yapılan araştırmada, Ağustos 2001 tarihinde 513.41 milyon internet kullanıcısı olduğu kestiriminde bulunuımuştur. Dolayısıyla, büyük hacimli bilgi yığınının, çok fazla kullanıcı grubu tarafından kullanıldığı karmaşık bir çevrim içi ortam karşımıza çıkmaktadır.

İnternet'e yönelik sunulan veriler, İnternet'in karmaşık doğası nedeniyle birer kestirim olmaktan öteye gidememektedir. Ancak, belirgin olan ve herkesin üzerinde anlaşabileceği nokta İnternet'in giderek büyüdüğü, sayısal açıdan basılı bilgi kaynaklarıyla karşılaştırılamayacak hacime ulaştığıdır.

Kuşkusuz, bu hacimdeki bilginin düzenlenmesi ve istenilen bilgiye ulaşılması hiç de kolay değildir. İnternet ve onun en sık kullanılan aracı World Wide Web (Web), bilgi erişimde önemli gelişmeler göstermesine karşın, Internet üzerinde yer alan bilgiye erişim ve seçme konusunda bir dizi sorunu da beraberinde getirmiştir. Bilindiği gibi arama motorları İnternet bilgi kaynaklarının dizinlenmesinde ve onlara erişimin sağlanmasında kullanılan araçlardır. Arama motorlarının İnternet'in tamamını dizinleyebilmeleri (bazılarının bunu iddia etmelerine karşın) olanaklı olmayıp, bunun doğał sonucu olarak internet üzerindeki tüm bilgi kaynakları ne yazık ki kullanıcılar için erişilebilir değildir. Arama motorlarının performanslarına yönelik yapılmış bir araştırmaya göre Northern Light (url ${ }^{4}$ ) İnternet'in $\% 16$ 'sını, Alta Vista (ur $\left.\left.\right|^{5}\right) \% 15,5$ 'ini, HotBot (url ${ }^{6}$ ) $\% 11.3^{\prime}$ ünü, Infoseek (url $\left.{ }^{7}\right) \% 8^{\prime}$ ini, Google $\% 7.8$ 'ini, Yahoo (url ${ }^{8}$ ) $\% 7.4$ 'ünü, Excite (url $\left.{ }^{9}\right) \%$ 5.6'sını, Lycos (url ${ }^{\dagger 0}$ ) \% $2.5^{\prime}$ ini, Euroseek (url ${ }^{11}$ ) $\% 2.2$ 'sini dizinleyebilmektedir (Browser News, 1999). Kuşkusuz bu araştırmadan sonra, arama motorları ve dizinleme servislerinin performanslarındaki gelişmelere paralel olarak yukarıdaki verilerin değişmiş olması da olasıdır. Ancak, İnternet'in tamamının dizinlendiğini ve üzerindeki tüm bilginin erişilebilir olduğunu da iddia etmek mümkün değildirr.

internet'in tamamının dizinleme servisleri tarafından kapsanamamasının yanı sıra erişim isabeti ve kesin isabet oranları (recall and precision) bir diğer sorunlu alandır. Yüzde 10-20'lik erişim isabeti ve kesin isabet oranı genelde kabul edilebilir olmakla birlikte, Web arama motorlarının, kesin isabet oranının \%1'den düşük olduğu iddia edilmektedir (Cathro, 1997). Soydal (2000, 
s. 86) tarafından yapılmış olan çalışmada, kesin isabet oranı Northern Light $\% 64$, Alta Vista ve Excite \% 50, Infoseek \% 49 ve HotBot \%48 olarak belirlenmiștir. Bir başka çalışmada ise, arama motorlarının ortalama kesin isabet oranının \%20 ila \%40 arasında değiştiği ifade edilmiştir (Gordon ve Pathak. 1999, s. 154). Sonuçlardaki bu farklılığın önemli nedenlerinden biri, Web'in büyüklüğü nedeniyle tamamının uygulama kapsamına alınamaması ve arama motorlarının performanslarında görülen değişimdir.

Sorunu örnekleme amacıyla, literatürde yer alan bir tarama, aynı arama motoru ve anahtar kelime ile son 3 yılda tarafımızdan tekrarlanmıştır. ANZWERS (url ${ }^{12}$ ) isimli arama motorunu kullanarak, "IETF" (Internet Engineering Task Force) anahtar kelimesi Ağustos 1997'de tarandığında 896.354 belgenin varlığı saptanmıştır (Cathro, 1997). Aynı terim, 5 Ağustos 1999'da tarandığında 91.017, 12 Nisan 2000'de 100.888, 22 Mart 2001'de 80.952, 7 Aralık 2001 'de ise 93.300 belgenin varlığı belirlenmiştir. Kuşkusuz aradan geçen süre içerisinde adı geçen arama motorunun performansında olumlu bir gelişme olmasına karşın varlığı tespit edilen belgelerin çoğuna kazara (içinde "ietf" harflerinin yanyana geldiği) erişildiği söylenebilir. Bu örnek, arama motorlarının bir Internet belgesi içindeki önemli ve rastgele kelimeler arasındaki ayırımı yapamadığını ve dolayısıyla taramayla ilişkisiz bir dizi bilgiyi de karşımıza çıkarabileceğini göstermektedir.

Kapsam, erişim ve seçim sorunlarına ek olarak. Web üzerinde yaratıımış olan bir sayfa ya da siteden başkalarınin haberdar edilmesi de bir başka sorun olarak karşımıza çıkmaktadır. Bilindiği gibi, dizinleme servisleri, dizinleme robotlarının siteleri ziyaret etmesiyle veya kendini kaydetme ile dizinleme işlemini gerçekleştirmektedir. Dizinleme robotları tarafından ziyaret edilmemiş (dolayısıyla dizinlenmemiş) bir Internet belgesinin kullanıcılar tarafından farkına varılabilmesi olanaklı değildir. Bunun yanı sıra. bazı dizinleme servisleri Internet belgelerini dizinlerken sadece meta bilgilerini (metadata) kullanmaktadır. Eğer bir belgenin metadatası yerieştirilmemişse, bu belge dizinlenemeyecek ve dolayısıyla potansiyel kullanıcılar tarafından farkedilmeyecektir.

Arama motoriarnn pertormans degentendime callsma ömehieri için bkz. Oppontheim. Morrs ve' Mckngh: 200 S Su'yda! 200n. 


\section{Metadata Nedir ?}

İnternet, sınıflaması olmayan büyük hacimli bir bilgi kaynağıdır. Bilindiği gibi, sınıflama yapmadan büyük hacimli bilgi yığınlarıyla başa çıkmak kolay değildir. Kütüphaneciler tarafından uzun süredir bilinen ve kullanılan bu olgu, İnternet üzerinde bulunan bilginin dizinlenmesinde, İnternet belgelerine metadata sınıflama bilgisinin eklenmeși gerekliliğiyle tekrar gündeme gelmiş ve metadata kavramı olarak karşımıza çıkmıştır.

Türkçe'de üst veri (Olgun ve Sever, 2000) olarak da kullanılan metadata** kavramını açıklamak üzere bir dizi tanım yapılmış olup, en basit ve sıkça kullanılan tanım "veri hakkında veri/bilgi" (data about data) şeklinde karşımıza çıkmaktadır. Literatürde yer alan tanımlardan bazıları şöyledir:

Metadata bir kaynağın ögelerini tanımlayan veridir. Bu nedenle bibliyografik veri olabildiği gibi içerik, kullanım koşulları, kapsam ve teknik ya da erişim özelliklerine ilişkin diğer tanımlamayı da içerebilir (Dempsey, 1998).

Web kaynakları ya da diğer şeyler hakkında makinece anlaşılabilir bilgi (W3 Consortium (url ${ }^{13}$ ), 2001).

Metadata veri hakkında bilgidir, ve bu nedenle bir eserin yazarı, oluşturulduğu tarih, ilişkili çalışmalara bağlantılar vb. temel bilgileri sağlar (Miller, 1996).

Tanımlar incelendiğinde metadata kavramının bibliyografik tanımlamayı içerdiği ve ifade ettiği açıkça görülecektir. Bu açıdan yaklaşıldığında bir kütüphanedeki kart katalog veya bir veri tabanındaki bibliyografik verileri de metadata olarak isimlendirmek olanaklıdır. Kart üzerindeki ya da elektronik ortamdaki bibliyografik veri, bir bilgi kaynağının metadatasıdır. Kuşkusuz bu noktada akla gelen ilk soru, kütüphanecilerin "bibliyografik veri" ya da "katalog bilgisi" diye adlandırdığı veriye niçin metadata denildiğidir? Aslında bu sorunun yanıtı oldukça basittir. Kütüphanecilerin uzun yıllardır araşırdığı ve kullandığı, büyük hacimli bilginin düzenlenmesi ve erişimi tekniklerinin, kütüphanecilik mesleği dışındaki meslek gruplarının konuya daha yoğun ilgi göstermesi ve gelenekse! kütüphane teknik ve yöntemlerini kendi meslek jargo-

\footnotetext{
* Kavram kargaşasına yol açmamak ıçin bu makalede metadata terimi tercih edilmiştir.
} 
nu içinde isimlendirmesinin yanı sıra, metadata kavramının bibliyografik tanımlamayla birlikte erişim, haklar, kullanım, format, orijinalliğini belirleme (authentication) ve güvenlik gibi dijital dünyaya ilişskin unsurları da içermesidir.

\section{Metadata Türleri ve Metadata ile İlgili Yaklaşımlar}

Metadata kavramının bibliyografik tanımlamadan, erişim yönetimine kadar geniş bir yelpazeyi içermesi nedeniyle, bu kavram Swetland (2000) tarafından 5 ayı (idari, tanımlayıcı, koruma, teknik ve kullanım) kategoriye ayrıımıştır. Bu kategoriler ve özellikleri özetlenerek aşağıda verilmiştir:

\begin{tabular}{|c|c|c|}
\hline Tür & Tanım & Örnek \\
\hline $\begin{array}{l}\text { İdari } \\
\text { (administrative) }\end{array}$ & $\begin{array}{l}\text { Bilgi kaynaklarının yönetiminde } \\
\text { kullanılan metadata }\end{array}$ & Sağlama bilgileri \\
\hline $\begin{array}{l}\text { Tanımlayıcı } \\
\text { (descriptive) }\end{array}$ & $\begin{array}{l}\text { Bilgi kaynaklarını tanımlama ve } \\
\text { kimtiklemede kullanılan metadata }\end{array}$ & Katalog kayıttarı \\
\hline $\begin{array}{l}\text { Koruma } \\
\text { (preservation) }\end{array}$ & $\begin{array}{l}\text { Bilgi kaynaktarının korunmasına } \\
\text { itişkin metadata }\end{array}$ & $\begin{array}{l}\text { Kaynakların fiziksel ve dijita! } \\
\text { korunmastna yönelik eylemlerin } \\
\text { dokümantasyonu }\end{array}$ \\
\hline $\begin{array}{l}\text { Teknik } \\
\text { (technical) }\end{array}$ & $\begin{array}{l}\text { Sistemin nasıl çałı̧acağı veya } \\
\text { metadatanın nasıl kullanılacağına } \\
\text { ilişkin metadata }\end{array}$ & $\begin{array}{l}\text { Yazılım ve donanım dokü- } \\
\text { mantasyonu. sayısallaştırma } \\
\text { bilgisi (formatı, sıkıştırma oranı, } \\
\text { güvenlik verisi gibi). }\end{array}$ \\
\hline Kullanım (use) & $\begin{array}{l}\text { Bilgi kaynaklarının kullanım türü ve } \\
\text { düzeyine ilişkin metadata }\end{array}$ & $\begin{array}{l}\text { Kullanım ve kullanıcıyı iz!eme, } \\
\text { bilginin birden fazla formatta tu } \\
\text { tulması (html, pdf gibi). }\end{array}$ \\
\hline
\end{tabular}

Metadata türlerinin ơtaya çıkışındaki en önemli etken, farklı yapıya sahip bilgi türlerinin (html metin, coğrafik görüntü, hareketli görüntü, tıbbi görüntü, arşiv belgesi gibi) farklı işlenmesi (sağlama, saklama, paketleme gibi) ve hizmete sunulması olduğunu söylemek olanaklıdır. Örnek vermek gerekirse, Directory Interchange Format (DIF) uydu görüntüleri için metadata sağlamaktadır (Miller, 1996). Text Encoding Initiative (TEI) (Ur| ${ }^{14}$ ), bilimsel anlamda 
yapılan araştırmalar için elektronik metinlerin yorumlanmasında bir rehber geliştirmeyi amaçlayan uluslararası bir proje olup, bir anlamda National Spatiał Data Infrastructure'ın (NSDI) (url ${ }^{15}$ ) devam eden bir gözden geçirmesi şeklindedir. ABD'ndeki bu uygulamaya karşılık, Birleşik Krallık'ta geçici olarak National Geospatial Database (url ${ }^{16}$ ) olarak adlandırılan proje, uzayla ilgili verilerin tanımlanmasını içeren karmaşık konular için benzer bir şema oluşturmayı amaçlamaktadır (Miller, 1996; TEl, 2001).

Var olan metadata projeleri son derece karmaşık ve uzmanlar tarafından yaratılıp bilgisayarlar tarafından anlaşılması (yorumlanması) gereken yapılardır. Örneğin Resource Organisation and Discovery'in Subject-based Services (ROADS) (url ${ }^{17}$ ), Joint Information Systems Commitee (JISC) (url ${ }^{18}$ ) tarafından finanse edilen, farklı konularda ve coğrafik alanlardaki internet kaynaklarına erişim sağlamak ve bu kaynakları tanımlayarak değerlendirmek amacıyla geliştirilen bir projedir. Geliştirilen yazılım, konu girişlerinin oluşturulmasına olanak sağlamakla birlikte, söz konusu kaynaklara ait kayıtların Web erişimli bir veri tabanıdır. Her bir kayıt, URL adresi, başık, tanım gibi alanları içerir ve tüm girişler taranabilmektedir (Kirriemuir, 1998).

Bu tür uzmanlaşmış metadata oluşturma/geliştirme yaklaşımlarının yanı sıra arama motoru yaklaşımı diye adlandırabileceğimiz, arama motorlarını Web belgeleri içindeki HTML meta tagları kullanmaya doğru götüren ikinci bir yaklaşımdan söz edilebilir. Örneğin Alta Vista arama motoru, sayfaların tanımlama (description) ve anahtar kelime (keywords) ögelerini kullanarak sayfaları dizinlemektedir (Miller, 1996).

Metadatanın işlenmesine yönelik karşımıza çıkan modellerden birisi olan Resource Description Framework (RDF), World Wide Web Konsorsiyum (W3C) tarafından önerilmektedir (Weibel, 1999). RDF, Web üzerindeki makinece anlaşılabilir bilginin uygulamalar arasında işlenebilirliğini ve Web kaynaklarının otomatik işlenmesini sağlayan olanakları içermektedir. RDF'in kullanıldığı çeşitli uygulamaları örneklemek gerekirse;

- Arama motorlarının kaynak keşfi yeteneğini artırmaktadır.

- Bir Web sitesinin içerik ve içerik jlişkilerinin tanımlanmasında (kataloglamada) kullanılmaktadir. 
- Akıllı yazılım araçları tarafından bilgi paylaşımı ve değişiminde kullanılmaktadır.

- Web sayfalarına kullanıcı erişim haklarının belirlenmesi, içerik erişim değerlerinin belirlenmesi ve sayfaların özel kullanım ve kopyalama haklarının belirlenmesinde kullanılmaktadır (Olgun, 1999).

\section{Metadata Standartları}

Elektronik ortamdaki bir bilgi kaynağının standart bir biçimde tanımlanması, bibliyografik verilere erişimi sağlayacak yazılımların kullanacağı standartları belirler ve verileri sistemden sisteme transfer edebilme olanağını yaratır. Aksi takdirde bibliyografik tanımlama kaosunun oluşması ve aynı kaynağın birden fazla kişi/kurum tarafından benzer emek, zaman ve maliyetin harcanarak tanımlanması gibi bir durum ortaya çıkacaktır. Kütüphanecilik mesleğinde bu durum yıllar öncesinde çözülmüş ve standart tanımlama kodları geliştirilmiş̧tir. Kütüphanecilik dışında gelişen metadata uygulamalarında ise. Content Standards for Digital Geospatial Metadata (url ${ }^{19}$ ), Encoded Archival Description (url ${ }^{20}$ ), Text Encoding Initiative. Categories for the Description of Works of Art (uri ${ }^{21}$ ), Dublin Core vb. bir dizi metadata standarti ortaya çımış bulunmaktadır. Bu standartlardan bazıları daha önce belirtildiği gibi (uydu görüntüleri vb.) belirli tip bilgi kaynaklarını tanımlamak ve onlara erişim sağlamak amacıyla geliştirilmişlerdir. Dublin Core (DC) gibi bazıları da farklı tipteki biłgi kaynaklarını tanımlamak ve tek bir tarama işlemiyle bunlara erişim sağlamak amacıyla geliştirilmişlerdir.

Kuşkusuz, Internet gibi son derece karmaşık bir çevrim içi ortamda, bir anda üzerinde görüş birliğine varı!mış bir standardın (hatta sonsuza dek) ofmasını beklemek oldukça iyimser bir yaklaşım olacaktır. Ancak, bu standartlar arasından bir ya da birkaçının diğerlerine oranla daha fazla kullanılacağını en azından akademik veya profesyonel yayıncılar gibi belirli çevrelerde daha fazla uygulama alanı bulacağını kestirmek olanaklıdır. Nitekim bu standartlar içinde Dublin Core, konu ve kaynak tipi ayırımı gözetmemesinden dolayı en fazla tanıtılan ve kullanılan standarttır. Dublin Core metadata element seti. 1995 ve 1996 yıllarında aralarında kütüphanecilerin de bulunduğu bir 
grup tarafından geliştirilmiş olup, W3 Consortium tarafından da desteklenmektedir. Aşağıda DC element setinin 15 data ögesi listelenmiştir (Dublin Core Metadata Initiative, 1999):

- Title (eser adı)

- Author or Creator (yazar ya da yaratan)

- Subject and Keywords (konu ve anahtar kelimeler)

- Description (tanım)

- Publisher (yayıncı)

- Other Contributors (diğer katkıda bulunanlar)

- Date (tarih)

- Resource Type (kaynak tipi)

- Format (biçim)

- Resource Identifier (kaynak tanımlayıcı)

- Source (kaynak)

- Language (dil)

- Relation (ilişki)

- Coverage (kapsam)

- Rights Management (hakların yönetimi).

\section{Metadata Oluşturma Araçları}

Gerek geleneksel olarak gerekse Internet ortamında olsun, metadatanın temel amacı, bilgi erişimi geliştirmek ve olanaklı kılmaktır. Fonksiyonlarının tamamının mesleki eğitim almış kütüphaneciler tarafından gerçekleştirildiği geleneksel kütüphane ortamında, makinece okunabilir kataloglama (MARC) gibi karmaşık metadata sistemlerj kaynak tanımlamada kabul edilebilir araçlardır. Ancak, daha karmaşık olan çevrim içi ortamda, sürekli yeni kaynaklar or- 
taya çıkmakta ve bu kaynaklar genellikle bireyler tarafından oluşturularak yaşatılmaktadır. Bu kaotik yapı nedeniyle bilgileri bulmak ve değerlendirmek kolay değildir. Tüm olumsuzluklarına karşın yeni bilgilere erişebilmekte arama motorlarını kullanmaktan başka seçeneğimiz de yoktur.

Böyle bir ortamda, metadatanın kullanııması kaçınılmazdır. Fakat, oluşturulacak metadatanın arama motorları ve insanlar tarafından yorumlanabilmeye uygun olması, herhangi bir Web yaratıcısının hazırladığı sayfayı ve içeriğini kolayca tanımlayabilmesi gerekir ki, en uygun tanımlama bilgilerini basit bir teknikle oluşturulabilsin. Metadata yaratmanın en uygun zamanı, tek bir işlemin parçası olarak, kaynak yaratılırken oluşturulmasıdır. Ancak, Internet üzerinde daha önceden üretilmiş bir dizi yararlı kaynağın var olduğu ve kişilerin geriye dönük olarak bunlara metadata eklemek isteyecekleri göz önüne alındığında bu tür uygulamalara yönelik olarak İnternet üzerinde ücretsiz elde edilebilen metadata yaratıcılarının (metadata generators) da bulunduğu unutulmamalıdır.

Metadata oluşturma araçlarını editörler ve yaratıcılar olmak üzere iki grupta toplamak olanaklıdır. Editör olarak adlandırılan araçlar, ekrana boş bir form getirirler ve boşluklar uygun ifadelerin girilmesiyle doldurulur. Destek yazılımı, giriten içeriği HTML tag haline getirir ve oluşturulan HTML tag bir belgeye kesilip yapıştırılabilir. Yaratıcı olarak adlandırılan araçlar ise mevcut HTML kodlu belgelerden metadatayı alarak içeriği HTML tag haline getirir. Yaratıcılar, HTML V3.2, HTML V4.0 ve XML gibi bir dizi çıktı seçeneği sunabilmektedir (National Library of Australia, 1999). Mevcut metadata oluşturma araçlarından bazıları aşağıda sunulmuştur:

\section{Editörler}

Nordic Web Index DC Metadata Template (url22):

Kuzey Avrupa ülkeleri için Dublin Core metadata yaratılmasına destek sağlamak amacıyla oluşturulmuş bir proje olarak karşımıza çıkmaktadır. Nordic Metadata Project'in sahip olduğu editör detaylı yardım hizmeti ile dikkat çekmektedir (Koch ve Borell. 1997). 
Gateway to Educational Materials (GEM) (ur ${ }^{23}$ ):

Amerikan Eğitim Bakanıı̆ı̆ın (ur| ${ }^{24}$ ) girişimiyle eğitimcilerin internet tabanlı ders planlarına ve diğer eğitim kaynaklarına erişimini artırmak amacıyla oluşturulan bir proje olup, bu kaynaklara erişimi sağlayan metadata standartları ve teknik mekanizmalar sunar. Bünyesinde binlerce ders planı, müfredat ve eğitimle ilgili kaynak bulunduran GEM, özeliikle öğretmenler için yararlı olmaktadır. GEM'in amacı, eğitimle ilgiii kaliteli kaynak koleksiyonu sağlayarak. kaynak keşif problemini çözmektir. Eğitimciler GEM'e bağlandıklarında; eğitim düzeyine, anahtar kelimeye veya konuya göre düzenlenmiş listeleri tarayabilmektedirler. GEM'de Şubat 2001 itibarıly 7800 'ün üzerinde kayıt yer almaktadir (GEM, 2001).

Reggie (ur| ${ }^{25}$ ):

Metadata editörü bir program aracılığıyla RDF formatı, HTML 3.2 ve HTML 4.0 standartların kullanarak farklı element setlerine ve farklı dillere dayalı olarak metadata yaratabilmektedir. Söz konusu diller İngilizce, italyanca, Fince, Fransızca, Almanca, İspanyolca, Norveçe ve Portekizce'dir. Ayrıca birbirinden farkı şemaları seçebilme olanağı da verebilmektedir. Bu şemalar Dublin Core, Global Information Locator Service (GILS) (ur| ${ }^{26}$ ), Australia New Zealand Land Information Council (ANZLIC) (url ${ }^{27}$ ), Australian Government Locator Service (AGLS) (ur|28), Education Network Australia (EdNA) $\left(\right.$ url ${ }^{29}$ ), IMS, GEM ve vCard şeklinde sıralanmaktadır (Resource Discovery Unit, 1998).

State Library of Tasmania's Generic Editor (url ${ }^{30}$ ):

Tasmania Devlet Kütüphanesinin (url ${ }^{31}$ ) bünyesinde bulunan Tasmania Online (url ${ }^{32}$ ) tarafından sağlanmaktadır. SuperNoteTab isimli metin editörü kullanılarak var olan HTML dosyalarına metadata koymak ve üzerinde değişiklikler yapmak olanaklıdır. Metadata Dublin Core (url ${ }^{33}$ ), AGLS ve ADMIN Core'u (url'34) içermektedir (Campbell, 1998). 
H-DCEdit (Hacettepe-Dublin Core Üstveri Elemanları Editörü):

Hacettepe Üniversitesỉ Bilgisayar Mühendisliği Bölümünde Türkçe elektronik kaynak içeriklerinin tanımlanmasında kullanılacak bir yazılım geliştirmek amacıyla yapılan yüksek mühendislik tezinin ürünüdür. 1999 yılında geliştirilen yazılım ilk Türkçe Dublin Core editörü olarak karşımıza çıkmaktadır (Küçük, Olgun ve Sever, 2000).

\section{Yaratıcılar}

Tag Gen (ur| $\left.{ }^{35}\right)$ :

Hiawatha island Software Şirketinin programı olan TagGen. metadata yaratan bir ürün olarak 1998 yılında piyasaya çıkmıştır. "Web üzerinde sitenizi görünür yapın" sloganıyla yola çıkan yazılım, Web sitesi tanıtımında ve bilgi yönetiminde söz sahibi olmak amacını gütmektedir (Hiawatha Island Software, 2001).

$D C$-dot $\left(\mathrm{urr}^{36}\right)$ :

United Kingdom Office for Library and Information Networking (UKOLN)'de (url ${ }^{37}$ ) çalışan Andy Powell tarafından geliştirilmiştir. DC-dot, tanımlanması istenilen Web sayfasına erişerek otomatik olarak metadatasını yaratmakta, ayrıca metadała üzerinde değişiklik yapabilme olanağı ${ }^{*}$ vermekte, farklı formatlara dönüş̧ürme işlemini de gerçekleştirilebilmektedir. Bu formatlar, USMARC, Summary Object Interchange Format (SOIF), Internet Anonymous Ftp Archives - IAFA/ROADS, TEI headers, GILS ve RDF'tir (Powell, 2000).

Medical Metadata Creator (ur| $\left.{ }^{38}\right)$ :

University of Newcastle Upon Tyne'in geliştirdiği ürün, tıbbi konulardaki Web sayfaları için metadata yaratmakla birlikte tıbbi konulara ilişkin kapsamlı anahtar kelimeler listesini de bünyesinde bulundurmaktadır (DSTC, 1998).

- Bu özelligi Dc-dot' aynı zamanda neładata editörü yapmaktadır. 


\section{Metadata Harvesting Protocol (MHP)}

Web, elektronik kaynakların tanımlanması ve dizinlenmesinin yanı sıra bunların kullanımına ilişkin bir dizi sorunu (lisans anlaşmaları, telif hakları, erişim hakları gibi) beraberinde getirmiştir. Web'in sunduğu hızlı erişim, aktarma olanakları sayesinde akademik dergiler hızı bir biçimde tam metin olarak Web üzerinde yer almaya başlamışlardır. Ancak, yayıncıların ücret ödemeden yazarından aldıkları bu yayınları, ücret karşığında (oldukça yüksek ücretler) kullanıma sunmaları, bu yazıları üreten kişi ve kurumları yeni arayışlara itmiştir (binlerce makale üreten bir üniversitenin, kendi yazarlarının yazılarının da yer aldığı veri tabanlarına ve ücretsiz yazısı alınan bir yazarın başka bir yazarın makalesini okuyabilmek için ücret ödemesini gözönüne alınız). Bu arayışlar sonucunda belge (metin, fotoğraf, hareketli görüntü vb.) üretenler, bu belgeleri herkese açık arşivler denilebilecek sunuculara yerleştirmeye başladılar. Böylelikle, üretilen belgeler daha fazla kişi tarafından ve ücretsiz olarak erişilmeye başlandı. Ancak bu arşivlere ve arşivlerde yer alan belgelere daha etkin erişimin sağlanabilmesi için uygun yöntem arayışları da başlamıştır.

Bunlardan biri The Open Archives Metadata Harvesting Protocol'dur. Bu protokol, dağıtık ağa dayalı bilgi hizmetlerini desteklemede (distributed networked information service) önemli bir alt yapı bileşenidir. Belge üreticilerinin belgelerinin metadatalarını oluşturmakarını kolaylaştıran bir mekanizma olarak Metadata Harvesting Protokolu, hızlı bir şekilde kullanım bułmuş ve fark। topluluklara yönelik sistem mimarilerini ve yeni hizmetleri olanaklı kılmaya başlamıştır. Daha yalın biçimde ifade edilecek olursa, MHP. sunucular üzerinde yer alan nesnelerin tanımlanmasına (belirlenmesi) yönelik dışarıdan gelen istekleri yanıtlayan bir ara yüzdür (Lynch, 2001). Bu arayüz sayesinde bir sunucu üzerindeki dijital nesnelerin neler olduğu tanımlama bilgileri yani metadata aracılığıyla öğrenilir ve/veya başkalarının bu metadataları elde etmelerine imkan tanınır (bu yüzden metadata hasadı yapmak anlamına gelen, "harvesting" ifadesi kullanılmıştır). 


\section{Sonuç}

Insanoğlunun łletişiminde dördüncü aşama olarak tanımlayabileceğimiz (dil, yazı, matbaa ve www) Web, kullanıcılarına iletişimde hız ve kolaylıklar sunmakla birlikte, bilgi erişim açısından bir dizi sorunu da beraberinde getirmiştir. Bu sorunları, çevrim içi ortamda yer alan belgelerin tamamının kapsanması, dizinlenmesi, seçimi, erişimi ve bu karmaşık çevrim içi ortamda farkedilebilmek olarak özetlenebilir.

Mevcut Web belgelerinin, belgenin tamamının dizinleme robotlarınca okunarak dizinlenmesi Web hacmi gözönüne alındığında olanaklı olmadığı gibi erişim isabeti ve kesin isabet açısından da en uygun çözüm yolu değildir. Ancak Web belgesinin tamamı yerine, standart bir biçimde oluşturulmuş bibliyografik verilerini okuyarak yapılan bir dizinleme, dizinleme robotlarının olduğu gibi erişim isabeti açısından arama motorlarının da performansını artıracaktır. Bu da, her bir Web belgesinin standart bir biçimde kimliklenmesi yani metadatasının oluşturulmasını zorunlu kılmaktadır.

Nitekim. kütüphaneciler büyük hacimli bilgi yığınlarıyla başa çıkmada bir dizi standart tanımlama kuralları, yöntemleri geliş̧tirmişler ve uygulamışlardır. Kütüphanelerde meslek eğitimi almış profesyonellerce uygulanan bu yöntem ve kuralların, ilgili eğitimi almamış kişilerce de uygulanabilmesini beklemek, hele İnternet gibi her düzey ve yaştan belge yaratıcısı ve kullanıcısının olduğu karmaşık bir ortamda, yyimserliğin ötesinde bir yaklașım olacaktır.

Web belgelerinin metadatasınt oluşturabilmenin bir dizi yoiu bulunmaktadır. Bunlardan biri belgeleri oluşturan kişi tarafından html taglarda tanımlama bilgilerinin verilmesi, diğeri ise bir araç aracılığıyla (editör ve yaratıcılar) metadatayı oluşturmaktır. Kuşkusuz bu bilgilerin standart bir biçimde ve içerikte olması farkıı uygulama yazılımlarının bu verileri kullanabilme olanağını sağlayacaktır. Bu gereksinimin doğal bir sonucu olarak standart metadata oluşturma yaklaşımları bir dizi farklı standardın oluşmasına neden olmuştur. Farklılığın en temel nedeni Web belgelerinin türü, işlenme biçimi ve hizmet amacıdır. Geliştirilmiş olan metadata standartları arasında özellikle Web belgeleri açısından Dublin Core Metadata Standardi'nın yayģınlaştırılmaya çalışıldığını söylemek olanakiıdır (aynı şekilde, arşivler için de Encoded Archival Description Metadata Standardı'nın önerildiğini söyleyebiliriz). Bir bașka yak- 
laşım, Metadata Harvesting Protocol adı altında başlatılan, sunucularda yer alan belgelerin metadatalarının hangi standartta olursa olsun bir ara yüz aracılığıyla (Metadata Harvesting Protocol) istemci/sunucu yazıımlar tarafından alınabilmesi ve verilebilmesini hedefieyen (Z39.50'ye benzer bir yapı) metadata oluşturan/toplayan yeni bir uygulamadır.

Batıda İnternet içeriğinin düzenlenmesi ve İnternet’te kaynak keşfi yeteneğinin artırılması konusunda bir dizi çalışma yapılırken, Türkçe içeriğin düzenlenmesi ve erişiminin etkinleştirilmesi konusuna yeterince yönelebildiğimizi söylemek olanaklı değildir. Kütüphaneciler olarak, büyük hacimli bilgi yığınlarının düzenlenmesinde ve hizmete sunulmasındaki deneyimlerimizi diğer meslek gruplarının üyeleriyle paylaşmak, geliştirmiş olduğumuz yöntem ve teknikleri aktarmak durumundayiz.

\section{Kaynakça}

Browser News. (1999). Statistics- search engines. [Çevrim içi]. Elektronik adres: http://www.upsdell.com/BrowserNews/stat_search.htm $[10$ Aralık 2001].

Campbell, D. (1998). Generic edit tool. [Çevrim içi]. Elektronik adres: http://www.dstc.edu.au/Research/Projects/metaweb/generic_tool.htm/ [12 Aralk 2001].

Cathro, W. (1997). Meładata: On overview. [Çevrim içi]. Elektronik adres: http://www.nla.gov.au/nla/staffpaper/cathro3.html [11 Aralık 2001].

Dempsey, L. (1998). Metadata: A UK HE perspective. [Çevrim içi]. Elektronik adres: http://www.ukoln.ac.uk/services/papers/bl/b/ri078/content/repor 27.htm [10 Aralık 2001].

DSTC. (1998). Analysis of current metadata creation tools. [Çevrim içi]. Elektronik adres: http://www.dstc.edu.au/Research/Projects/metaweb/toolpost.html [10 Aralık 2001].

Dublin Core Metadata Initiative. (1999). Dublin Core Metadata Element Set. Version 1.1; Reference Description. [Çevrim içi]. Elektronik adres: http:/dublincore.org/documents/1999/07/02/dces/ [10 Arailk 2001]. 
GEM. (2001). The Gateway to Educational Materials. [Çevrim içi]. Elektronik adres: http://www.geminfo.org/networker.html [11 Aralık 2001].

Gordon, M. ve Pathak, P. (1999). Finding information on the World Wide Web: the retrieval effectiveness of search engines. Information Processing and Management, 35(2): 141-180.

Gray, M. (1996). Web growth summary. [Çevrim içi]. Elektronik adres: http://www.mit.edu/people/mkgray/net/web-growth-summary.html [11 Aralık 2001].

Hiawatha Island Software. (2001). HiSoftware-TagGen. [Çevrim içi]. Elektronik adres: http:/www.hisoftware.com/taggen.htm [12 Aralık 2001].

Kirriemuir, J. (1998). What is ROADS? [Çevrim içi]. Elektronik adres: http:/Www.ukoin.ac.uk/metadata/roads/what/ [05 Eylül 2000].

Koch, T. ve Boreli, M. (1997). Dublin Core Metadata Template. [Çevrim içi]. Elektronik adres; http:/www.lub.lu.se/cgi-bin/nmdc.pl [12 Aralık 2001].

Küçük, M. E., Olgun, B. ve Sever, H. (2000). Application of metadata concepts to discovery of Internet resources. Tatyana Yakhno (ed.) Advances in information systems: first international conference; proceedings/ ADVIS nono, izmir, Turkey, October 25 27, noop içinde (3.304.313). Berlin: Springer.

Lowe, D. (2000). Improving Web search relevance: using navigational structures to provide a search context. [Çevrim içi]. Elektronik adres: http://ausweb.scu.edu.au/aw2k/papers/lowe/paper.html [11 Aralık 2001].

Lynch, C. (2001). Metadata Harvesting and the Open Archives Initiative. ARL Bimonthly Report [Çevrim içi], 217: 1-9. Elektronik adres: http://www.arl.org/newsltr/217/mhp.html 217: 1-9. [14 Aralık 2001].

Miller, P. (1996). Metadata for the masses. [Çevrim içi]. Elektronik adres: http:/www.ariadne.ac.uk/issue5/metadata-masses/ [10 Aralık 2001].

National Library of Australia. (1999). Meta matters: Tools. [Çevrim içi]. Elektronik adres: http://www.nla.gov.au/meta/tools.html 
Nefcraft. (2001). Netcraft Web Server Survey. [Çevrim içi]. Elektronik adres: http:/www.netcraft.com/survey/ [11 Aralık 2001].

Nua. (2001). How many online. [Çevrim içi]. Elektronik adres: http:/www.nua.ie/surveys/how_many_online/ [11 Arallk 2001].

Olgun, B. (1999). Dublin Core üstveri elemanlar editörü. [Çevrim içi]. Yayımlanmamış yüksek mühendislik tezi. Hacettepe Üniversitesi, Ankara. Elektronik adres: http://ata.cs.hun.edu.tr/ km/baha/rdf.html [10 Aralık 2001].

Olgun, B. ve Sever H. (2000). Kaynak keşif yeteneğinin arttırılması için İnternet kaynaklarının içeriklerinin standart biçimde tanımlanması. Bilgi Dünyası, 1(1): 56-88.

Oppenheim, C, Morris, A. ve Mcknight, C. (2000). The evaluation of WWW search engines. Journal of Documentation. 56 (2): 190-211.

Powell A. (2000). DC-dot. [Çevrim içi]. Elektronik adres: http://www.ukoln.ac.uk/metadata/dcdot/ [12 Aralık 2001].

Resource Discovery Unit. (1998) Reggie-metadata editor. [Çevrim içi]. Elektronik adres: http://metadata.net/dstc/ [12 Aralık 2001].

Soydal, i. (2000). Web arama motorlannda performans değerlendirmesi. Yayımlanmamış bilim uzmanığı tezi. Hacettepe Üniversitesi, Ankara.

Sullivan D. (2001) Search engine sizes. The Search Engine Report. August 15. [Çevrım içi]. Elektronik adres: http:/searchenginewatch.com/reports/sizes.html [11 Aralık 2001].

Swetland A. J. (2000) Introduction to metadata: Setting the stage. [Çevrim içi]. Elektronik adres: http://www.getty.edu./research/institute/standards/intrometadata/2_articles/index.html [11 Aralık 2001].

TEI (2001). What is the TEl Consortium. [Çevrim içi]. Elektronik adres: http://www.tel-c.org/Consortium/index.html [10 Aralık 2001].

W3 Consortium. (2001). Metadata and resource description. [Cevrim içi]. Elektronik adres: http:/www.w3.org/Metadata/ [10 Aralık 2001].

Weibel, S. (1999). The state of the Dublin Core Metadata Initiative. D-Lib Magazine [Çevrim içi], 5(4). Elektronik adres: http://dlib.org/dlib/april99/04weibel.html [11 Aralık 2001] 


\section{URL Listesi}

1 Netcraft - http://www. netcraft.com/

2 Google - http://www.google.com/

3 Nua - http://www.nua.ie/

4 Northernlight - http:/www.northernlight.com/

5 Alta Vista - http://www. altavista.com/

6 HotBot - http://www. hotbot.com/

7 Infoseek - http:/www.intoseek.com/

8 Yahoo - http://www yahoo.com/

9 Excite - http://www.excite.com/

10 Lycos - http:/www.lycos.com/

11 EuroSeek - http //ww.euroseek.com/

12 ANZWERS - http://www.anzwers.com.au/

13 W3 Consortium - http://www.w3.org/

14 Text Encoding Initiative - http://www,tei-c.org/

15 National Spatial Data Infrastructure-http://www.fgdc.gov/nsdi/nsdi.html

16 National Geospatial Database - http:/www.ngdf.org.uk/

17 Resource Organisation and Discovery in Subject-based Services http://www.ilrt.bris.ac.uk/roads/

18 Joint Information Systems Committee - http://www.jisc.ac.uk/

19 Content Standards for Digital Geospatial Metadata http:/www.fgdc.gov/metadata/contstan.html

20 Encoded Archival Description - http://cweb.loc.gov/ead/

21 Categories for the Description of Works of Art - http://is.gseis. ucla.edu/impact/995/Cdwa/HOMEPAGE. HTML 
22 Nordic Web Index DC Metadata Template - http://www.lub.lu.se/ cgi-bin/nmdc.pl

23 Gateway to Educational Materials - http://www.geminfo.org/

24 US Department of Education - http://www.ed.gov/

25 Reggie - http://metadata.net/dstc/

26 Global Information Locator Service - http://www.gils.net/

27 Australia New Zealand Land Information Council - http://www. anzlic.org.au/

28 Australian Government Locator Service - http:/www.naa.gov.au/recordkeeping/gov_online/agls/summary.html

29 Education Network Australia - http://www.edna.edu.au/

30 State Library of Tasmania's Generic Editor - http://www.dstc.edu.au/ Research/Projects/metaweb/generic_tool.html

31 State Library of Tasmania - http://www.statelibrary.tas.gov.au/

32 Tasmania Online - http://www.tas.gov.au/

33 Dublin Core - http://dublincore.org/

34 ADMIN Core - http://metadata.net/admin/

35 TagGen - http:/www. hisoftware.com/taggen.htm

36 DC-Dot - http://www.ukoln.ac.uk/metadata/dcdot/

37 UKOLN - http://www.ukoln.ac.uk/

38 Medical Metadata Creator - http://medir.ohsu.edu/biç-informatics/ ebm/latest.htm 